\title{
Acolhimento e (des)medicalização social: um desafio para as equipes de saúde da família
}

\author{
User embracement and social (de)medicalization: \\ a challenge for the family health teams
}

\author{
Charles Dal canale Tesser $^{1}$ \\ Paulo Poli Neto ${ }^{2}$ \\ Gastão Wagner deSousa Campos ${ }^{3}$
}

\footnotetext{
${ }^{1}$ Departamento deSaúde Pública, Centro deCiências daSaúde. Campus

Universitário Trindade 88040-900 Florianópolis SC charlestesser@ccs.ufsc.br

${ }^{2}$ Centro de Filosofiae

Ciências H umanas,

UniversidadeFederal de

SantaCatarina.

${ }^{3}$ Departamento deM edicina

Preventiva, Faculdadede

Ciências M édicas,

UniversidadeEstadual de

Campinas.
}

Abstract This article discusses the relation between sheltering practice and social medicalization in the primary care. It begins with a revision about social medicalization and mentions some influences concerning the organization of the Brazilian primary care. It also indicates that the ground of receptivity proposal was provided by those influences. It argues the potentiality to accomplish the sheltering with a demedicalization and interdisciplinary action and its reverse effect, when restricted simply to emergency medic care. There are hereby suggested changes in the management and organization of routines, agendas as well as collective and individuals activities of the professionals with the intention to reduce medicalization. The conclusion favors the expansion of experimentation on sheltering as a strate gy in dealing with unexpected events and with primary care spontaneous demand, al ways watching out for its medicalization potential. Key words User embracement, Social medicalization, Family Health Program, Primary care
Resumo Esteartigo discutea relação entre a prática do acolhimento na atenção primária (Programa/Estratégia Saúde da Família) e o processo de medicalização social. I nicia com a síntese de uma revisão sobre medicalização social e a indicação de influências históricas e conceituais sobre a organização da atenção básica brasileira, que prepararam terreno para a emergência da proposta do Acolhimento. Argumenta sobrea possibilidade de se realizar o Acol himento numa lógica desmedicalizante e interdisciplinar e sobre a forte potencialidade inversa, quando o Acolhimento é restrito a simples pronto-atendimento médico. Sugere mudanças em rotinas, agendas e atividades profissionais individuais e coletivas, terapêuticase de promoção à saúde, para que cada equipe possa acolher seus usuários minimizando a medicalização. Conclui a favor de experimentações do A colhimento como estratégia para se lidar com eventos inesperados e com a demanda espontânea, sempre tomando cuidados quanto ao seu potencial medicalizador.

Palavras-chave Acolhimento, M edicalização social, Programa Saúde da Família, Atenção primária 
Introdução

A construção do Sistema Ú nico de Saúde (SUS) é uma política de Estado democrática e de bemestar, que vem ampliando o acesso ao cuidado à saúde. Uma política na contramão da tendência neoliberal hegemônica na sociedade e no Estado brasileiro ${ }^{1}$. Com o SUS, vem ocorrendo uma progressiva expansão da cobertura da população brasileira em programas de atenção à saúde, ao mesmo tempo quese manteve a hegemonia do modelo biomédico na maioria dos programas ofertados. Isto vem acontecendo notadamente a partir da década de 90 , com a expansão da rede básica estimulada pelo Programa Saúdeda Família(PSF), depois Estratégia Saúde da Família (ESF), bem como pela extensão de serviços de pronto-atendimento e da atenção hospitalar². Caberia perguntar o que essa expansão do acesso representa em termos de medicalização social, processo já em curso através da mídia, da cultura e do mercado.

A medicalização social é um processo sociocultural complexo que vai transformando em necessidades médicas as vivências, os sofrimentos e as dores que eram administrados de outras maneiras, no próprio ambiente familiar e comunitário, eque envolviam interpretações etécnicas de cuidado autóctones. A medicalização acentua a realização de procedimentos profissionalizados, diagnósticos e terapêuticos, desnecessários e muitas vezes até danosos aos usuários. Há ainda uma redução da perspectiva terapêutica com desvalorização da abordagem do modo de vida, dos fatores subjetivos e sociais relacionados ao processo saúde-doençą-6.

O PSF, na sua criação, propunha-se a supe rar essa tradição medicalizante, substituindo-a por uma nova concepção apoiada na Promoção à Saúde. Em alguma medida, a introdução dessa estratégia de fato produziu uma saudável tensão paradigmática entre a biomedicina e abordagens mais ampliadas ${ }^{7}$. No entanto, não houve uma reorganização da formação de especialistas mé dicos enfermeiros em escala suficiente para sustentar esse tipo de reforma cultural. Além disso, o PSF, inicialmente, orientou as equipes a lidar centralmente com os programas de saúde, com protocolos diagnósticos eterapêuticos definidos. Observou-se, contudo, que não havia recomendações sobre como lidar com a demanda espontânea que recorre aos serviços de atenção básica ou como atender aos imprevistos tão frequentes e inevitáveis no cuidado à saúde.

Procurando responder a essas lacunas, apareceu a proposta de Acolhimento, divulgada e recomendada no SUS por meio da Política Nacional de Humanização ${ }^{8}$. O Acolhimento envolve arranjos institucionais de difícil execução, propõe-se a trabalhar a demanda espontânea, a ampliar o acesso e concretizar a missão constitucional da APS no SUS, de ser a principal "porta de entrada" do sistema.

Entretanto, constata-se que ao reorganizar o contato dos serviços de APS com os usuários e suas demandas, a estratégia do Acolhimento tem um potencial de ativar o processo de medicalização social numa dimensão microssocial e local. Analisar a relação entre diferentes estratégias de Acolhimento e suas possibilidades de medicalização ededesmedicalização éo objetivo desteensaio.

O campo de práticas subsidiárias da discussão é amplo: um autor foi médico generalista nove anos (dois na coordenação) em serviço básico de uma comunidade rural, que incluía um pronto-atendimento (PA) (5 mil hab.); trabaIhou um ano em centro de saúdecentrado em PA de outra pequena cidade paulista; três anos no PSF de uma grande cidade (1 milhão de hab.), em serviços com práticas de acolhimento distintas; e dois anos coordenando estágios de internato médico em vinte centros de saúde com PSF em cidade de médio porte ( 300 mil hab.). Outro autor trabalhou dois anos em uma equipe de PSF isolada em bairro rural e depois mais um ano em centro de saúde com cinco equipes de Saúde da Família. 0 terceiro autor foi gestor e assessor de serviços de APS nas décadas de $80 \mathrm{e}$ 90 esecretário deSaúde da grandecidademencionada, em que o Acolhimento era diretriz institucional importante. A pesar de não ter havido coleta sistemática de dados nessas experiências, da sua diversidade e análise foram extraídos pontos críticos para discussão, que não se quer exaustiva nem conclusiva.

\section{Sobrea medicalização social}

Ao revisar estudos das ciências sociais sobre 0 tema da medicalização, $\mathrm{N} \mathrm{ye}^{9}$ demonstra como ele é compreendido de maneiras diferentes ao longo do tempo. Nos primeiros trabalhos, significava apenas a ampliação da assistência médica e de novas técnicas terapêuticas, atéa sua posterior conversão a um significado mais amplo, referente à crescente incorporação de diferentes aspectos da condição humana, sejam sociais, econômicos ou existenciais sob o domínio do medicalizável; isto é, do diagnóstico médico, da terapêutica, da patologia etc. Esses estudos surgem 
justamente na segunda metade do século XX, em que houve uma grande expansão da medicina, com a utilização de novos exames diagnósticos (especialmente de imagem), novas classes de medicamentos, novas técnicas e materiais cirúrgicos e novas áreas de pesquisa (genética, imunologia, virologia etc.).

Deacordo com o conceito debiopolítica foucaultiano, esse processo se origina no momento em que a regulação médico-sanitária da vida é utilizada como estratégia para ordenar a relação entre o Estado e indivíduos ${ }^{10}$. A medicina, para Foucault, é uma das instituições ou disciplinas, assim como a escola, o exército, os presídios, que auxiliam e constituem o Estado moderno nessa tarefa de organizar a vida coletiva e individual. Ao contrário de outros autores, Foucault defendea existência de positividadenessa relação entre o Estado e os indivíduos, em que estes não são simplesmente sufocados por uma superestrutura, mas que haveria uma produção de subjetividade que alimenta essa rede de poder. No caso da medicina, tolera-se a interferência dessa rede de saber-poder que redistribui os corpos, reorganiza o espaço, introduz reformas na vida cotidiana, porque produz positividades, resolve problemas médicos, possui certa eficácia curativa.

Foucault ${ }^{11}$ afirma que a biomedicina não é resultado de uma progressão histórica linear, impulsionada por descobertas científicas, mas consequência de uma mudança na maneira de ver e de entender a clínica, em que se separa a doença do doente nas chamadas espacializações da doença. Ao se organizar em torno de uma teoria das doenças e da anatomoclínica, o saber médico se abre para uma medicalização de novos espaços.

0 imaginário biomédico dominante na biomedicina apresenta algumas características marcantes, centrais ao chamado paradigma biome cânico ou flexneriano: visão do corpo humano como máquina; visão das doenças como coisas concretas, que não variam em pessoas e lugares, e que surgem como defeitos das peças dessa máquina, de natureza material. As lesões materiais ou germes são as causas últimas das doenças e demandam exames que vasculham o interior do corpo para diagnóstico. 0 tratamento é centrado preferencialmente em medicamentos quimicamente purificados ecirurgias. 0 relacionamento é autoritário com os doentes (paradigma do cuidado hospitalar), que devem se submeter aos profissionais e aprender deles o saber científico, único verdadeiro para cumprimento eficaz do tratamento e prevençãa ${ }^{5,12,13}$.
A ação profissional nesse ambiente de ideias e valores tende a transformar toda queixa em síndrome, "transtorno" ou doença de caráter biológico, desligando-a da vida vivida pelo doente, considerando-a realidade distinta e independente. Em doenças crônicas, cada vez mais frequentes, ocorre 0 isolamento de fatores de risco que se destacam da vida e passam a ser considerados causas isoladas combatidas através de comportamentos "saudáveis" prescritos do mesmo modo que drogas e cirurgias. Estas últimas, mais o fetiche dos exames complementares, são o carrochefe da cultura medicalizada. Assim, na interpretação e na interven ção biomédicas há nítida tendência medicalizante ${ }^{3,14}$.

Há certo consenso sobre o nascimento e as características da biomedicina; mas o mesmo não ocorre em relação ao binômio autonomia/heteronomia. Paralllich ${ }^{3}$, o excesso defunção edeuso de uma ferramenta social-tecnológica ou o seu monopólio pode induzir ao que denominou de contraprodutividade: uma ação paradoxal em que 0 resultado é o contrário do esperado: hospital que produz doença, trânsito queproduz engarrafamentos. A ação médica padeceria desse mal. Ao causar uma iatrogênese social ecultural, além da iatrogenia clínica individual, as pessoas são transformadas em consumidores vorazes de mais e mais cuidado e de tecnologias especializadas e tornam-se dependentes. Isso diminuiria a autonomia e a capacidade de agir sobre a vida e sobre o meio para manter, resgatar e ou ampliar a saúde e a liberdade - vistas como coeficiente de liberdade vivida e capacidade de instituir normas vitais, seguindo Canguilhem ${ }^{15}$. Na visão de Illich ${ }^{3}$, a saúde pode, ao contrário do que parece, estar decaindo, já que a capacidade de ação das pessoas sobre sua própria vida, ambiente e saúde, sobre suas vivências e sofrimentos cotidianos, poderia estar diminuindo.

Para Freidson ${ }^{16}$, que estuda o processo de medicalização como um exemplo da profissionalização, a medicina modernaéessencialmenteheteronômica. 0 autor ocupa-se de percorrer 0 caminho que levou a medicina de uma ocupação a uma profissão, quando, por virtude de sua posição autoritária na sociedade, vem a criar a substância do seu próprio trabalho. A partir do momento em que se tornam oficiais, as profissões definem os objetos de seu trabalho, abrindo espaço para que interesses corporativos interfiram nesse processo. Além disso, a determinação de profissões "oficiais" impedeque outras ocupações deem-se a chance da exposição empírica, da experimentação do erro e do acerto, da sua aplicação em grande número de casos ou pessoas. 
Mas há autores com visão mais otimista em relação a esse processo, que avaliam não haver uma aceitação passiva por parte da população, identificando até formas de contestação do poder das instituições. Williams e Calnan ${ }^{17}$ lançam mão das formulações teóricas de Giddens para se contraporem ao pessimismo da década de 1960. Elesidentificam a existência de maior reflexividade social na modernidade tardia, o quesignificaria uma suscetibilidade maior a vários aspectos da atividade social em razão de novas informações e conhecimentos: a medicina tornase uma empresa cada vez mais reflexiva em termos de sua base de conhecimento, sua organização social e a natureza da prática médica diária.

Segundo os autores, há espaço de crítica à medicina moderna e a mídia tem um papel crucial de desmistificação da ciência e da tecnologia ${ }^{17}$. Haveria um empoderamento da população, já que as pessoas estão mais conscientes das fragilidades das corporações. A população, munida de maior acesso à informação através da Internet ou de outros meios de comunicação, poderia estar mais consciente dos custos, benefícios emal efícios da medicalização de suas vidas ${ }^{18}$.

Nos seus escritos tardios, Illich ${ }^{19}$ identifica haver, de fato, uma desmedicalização, entretanto a medicina estaria perdendo espaço para outras áreas - estética, moda, educação física, saúde pública - que difundem uma concepção doentia de cuidado com o corpo e da busca da saúde perfeita. N os seus últimos trabalhos, Illich considera que 0 fato de as pessoas hoje buscarem mais informações sobre saúdee haver maior preocupação com a própria saúde representaria outra forma grave de iatrogenia4.

A medicina cedeu espaço para outras áreas porque surgiu outra concepção sobre o corpo a corpolatria - que vai resultar na busca patogê nica pela saúde ${ }^{19}$. 0 maior acesso às informações sobre doenças e hábitos saudáveis que poderia representar um empoderamento da população diante da corporação médica representaria ape nas o efeito de um tempo em que todas as atividades humanas são maciçamente relacionadas à saúde e há uma neurose coletiva em busca da saúde perfeita, chamada de "higiomania" por Nogueira ${ }^{20}$. Freidson ${ }^{16}$, em releitura posterior de seu próprio trabalho, também considera ter havido nos últimos anos uma diminuição da autonomia técnica do profissional médico, mas quea profissão como um todo jamais teve o poder que detém hoje.

É importante ressaltar que apesar da ênfase na profissão médica, a medicalização não se res- tringe a ela, mas ao processo presente em todas as áreas da saúde de categorizar sofrimentos e sintomas em diagnósticos, oferecer explicações naturalizadas e terapias reduzidas ante a complexidade dos problemas.

No entanto, outra característica mais recente de nossa sociedade é a expansão da ênfase biomédica nos riscos, notadamente após a possibilidade exemplar de seu "tratamento" via quimioterapia (vejam-se as estatinas) , o que parece estar gerando uma medicalização importante não só do presente, mas também do futuro, acentuada ainda mais pelas promessas alardeadas pela genética. Isso faz pensar que, no geral, a medicalização mantém-se firme e progressiva, a sociedade (do risco) está cada vez mais dependentede informações e tecnologias médicas, ao mesmo tempo que os indivíduos são instados a responsabilizar-se em relação a sua própria saúde $e^{21}$.

Concepções que influenciaram

a Atenção Primária brasileira

e o Acolhimento

A organização dos primeiros Centros de Saúde no Brasil, durante a primeira metade do século XX, e sua posterior expansão até os anos 80 foi influenciada pela concepção norte-americana de SaúdePública, segundo a qual o cuidado em saúde comporia dois grandes sistemas: um de assistência clínica - hospitais, serviços de urgência, consultórios etc. - e outro de Saúde Pública (vigilância). Os Centros de Saúde seriam um dos operadores do setor de Saúde Pública. Eram organizados em programas preventivos e de controles de doença: puericultura, prénatal, tuberculose e outros problemas de rel evância coletiva. Segundo essa tradição, a APS é vista como espaço para a prevenção à saúde, não para o exercício daclínica.

Posteriormente, com o surgimento da Saúde Coletiva no Brasil e da Promoção da Saúde no Canadá, reforçou-se essa tendência. O PSF, criado em 1994, foi bastante influenciado por essa perspectiva, destacando-se as diretrizes da intersetorialidade, deintervenção no território, a abordagem da família ou de coletivos, que persistem até hoje $e^{22}$. Note-se que a abordagem clínica individual era justificada por programas de saúde, com temas sanitários considerados relevantes pela epidemiologia.

A introdução dalógica epidemiológica no contexto da organização do dia a dia, proposta pela "programação em saúde" 23 e pela "Vigilância à 
Saúde"24, tampouco facilitou 0 acesso aos usuários. Tal lógica, introduzindo critérios epidemiológicos para priorização de ações de vigilância, prevenção, tratamento e controle dedoenças, criando grupos prioritários, reservas de vaga e direcionamentos deagenda, acabou convergindo para a desval orização da demanda espontânea, o que ten deu a reforçar a rigidez das agen das na prática, ainda quando isso não fosse buscado.

Outra concepção quetem influenciado, concretamente, a APS no Brasil é a estratégia de garantir-se acesso ao SUS mediante a multiplicação de serviços de PA. Pouco teorizada e investigada, esta alternativa tem presença em municípios e junto a autoridades do Poder Executivo, já que prioriza 0 acesso sobre a qualidade e oferece um serviço de gestão mais simples do quea equipeinterdisciplinar do PSF. Ao contrário da tradição anterior, não valoriza programas, responsabilidadepor território, seguimento de casos, ações educativas ou comunitárias. Vários municípios brasileiros, na prática, adotaram esse estilo de organização, que utiliza o pronto-socorro de hospitais e prontos-atendimentos isolados como modelo de APS. As consequências negativas do PA são bastante consensuais no campo acadêmico: medicalização, baixa autonomia dos usuários, ineficácia antedoenças crônicas, baixo aproveitamento do potencial de outros profissionais de saúde e do trabal ho em equipe eincapacidade deatuação em determinantes de saúdecoletivos ${ }^{25}$.

A pesar da correção do olhar crítico da Saúde Coletiva para com a clínica biomédica, já hátempos $\mathrm{Campos}^{26}$ e M erhy $^{27}$ advertiam que o saber epidemiológico não deve ser tomado como único potente para definição de necessidades, prioridades e problemas de saúde. Deve ser articulado com as necessidades sentidas, expressas em demanda cotidiana aos serviços de saúde e por meio da participação social na gestão do SUS (Conselhos de Saúde) 8,28-30.

Há, entretanto, uma terceira forma para se conceber a APS originária dos países queimplantaram sistemas nacionais de saúde, particularmentena Europa. N este caso, a APS évista como porta de entrada de um sistema integrado em rede de atenção ambulatorial, hospitalar etc. N essa tradição, valoriza-se a capacidade clínica para resolver problemas de saúde ${ }^{31}$.

Vale ainda considerar que os serviços públicos brasileiros de APS não superaram o padrão dominante em que a organização estatal em geral ea instituição médica tendem a produzir uma relação ritual izada, en rijecida e burocratizada com os usuários. Nesse enquadramento a atividade profissional costuma resumir-se a programas, protocolos e procedimentos padrão, como "consulta", por exemplo. 0 modelo típico de serviços públicos deAPS no Brasil podeser descrito como de uma "repartição" ou "ambulatório" em que o usuário chega como a uma prefeitura ou outro órgão público: há horários rígidos, comumente comerciais, com guichês onde funcionários administrativos (recepcionistas ou similares) fazem uma "recepção". Há um "cardápio" de serviços organizados em forma de agenda, centrada em consultas médicas e, quando muito, de enfermagem (além de outros serviços como vacinações, curativos etc.). 0 número de vagas na agenda é limitado e elas são preenchidas por ordem de chegada, em geral. Acabadas as vagas, acabou 0 acesso ao cuidado. Uma mistura de lógica deconsultório médico privado dentro de/e sinérgica com uma repartição pública.

Foi a partir da crítica a essa situação ebuscando superá-la que se construiu a proposta do AcoIhimento no seu aspecto institucional, almejando dar viabilidade organizacional à missão ética e à ambição política de concretizar a universalidadee equidade na interação dos serviços com os usuários. Em vez deserviços apenas centradosem agendase procedimentos (consultas) ou em ações programadas para agravos e doenças epidemiologicamente relevantes, serviços estruturados para trabal har a partir de problemas reais dos usuários sob sua responsabilidade personalizada, sem deixar de fazer ações programadas e vigilância.

Acolhimento e organização do trabal ho nas equi pes de saúde da família

0 Acolhimento envolve um interesse, uma postura ética e de cuidado, uma abertura humana, empática e respeitosa ao usuário, mas ao mesmo tempo implica avaliação de riscos e vulnerabilidades, eleição de prioridades, percepção de necessidades clínico-biológicas, epidemiológicas e psicossociais, que precisam ser consideradas. I sso permite, em tese, hierarquizar necessidades quanto ao tempo do cuidado (diferenciar necessidades mais prementes de menos prementes); distinguir entre necessidades desiguais e tratá-las conforme suas características. Assim, ele envolve, supõeeestimula um sentido ético individual e coletiv0 ${ }^{32}$, assumido como fundamental para orientar a postura do profissional. M as envolve também questões de organização e prática do trabalho, tópico enfocado aqui na sua relação com a medicalização social. 
O Acolhimento é uma proposta voltada para mel horia das relações dos serviços de saúde com os usuários. N este caso, concretiza-se no encontro do usuário que procura o serviço espontaneamente com os profissionais de saúde, em que há uma escuta, um processamento de sua demanda e a busca de resolução, se possível.

0 Acolhimento está baseado também em um direito constitucional dos indivíduos que éo direito de acesso aos serviços de saúde. Como a APS é a porta de entrada desse sistema, é necessária uma estratégia que permita um fluxo facilitado das pessoas. Além disso, uma das características para a efetividade e o sucesso da APS é 0 fácil acesso ${ }^{33}$, motivo que torna crucial o desenvolvimento de arranjos institucionais e práticas profissionais facilitadores desse acesso.

A proposta de Acolhimento no Brasil sugere formas de atenção à demanda espontânea que não impliquem simplesmente maior acesso à consulta médica, mas propõe-se a servir de elo entre necessidades dos usuários e várias possibilidades de cuidado. Nesse sentido, foi original e inovadora. No Acol himento foram incluídos vários profissionai ${ }^{34}$. A ideia seria retirar do médico o papel de único protagonista do cuidado, ampliar a clínica realizada pel os outros profissionais e incluir outras abordagens e explicações possíveis (que não somente as biomédicas) para os adoecimentos e demandas.

Pode-se considerar que estão envolvidas na proposta do Acolhimento "duas pernas" fundamentais: uma ética e política, em que se almeja melhorar a postura dos profissionais no contato com a clientela; eoutra degestão edemodelo assistencial, que visa reformular a tradição burocrática e rígida ao melhorar o acesso eo cardápio de ofertas do serviço, flexibilizar eampliar a clínica, facilitar o cuidado interdisciplinar. São necessárias estas "duas pernas" andando juntas harmoniosamente para viabilizar econcretizar o Acolhimento.

Isso pressupõe uma nova cultura de trabaIho, bem como novas formas de organizar e ge rir esse trabalho. A equipe de referência (equipe de saúde da família) assume a responsabilidade de acolher os usuários nas suas demandas, ouvilos, negociar com eles etentar resolver seus problemas da melhor e mais rápida forma possível. Para tanto, um profissional (técnico ou auxiliar de enfermagem, geralmente) precisa estar à disposição para realizar o primeiro acolhimento, que por sua vez substitui e torna dispensável a recepção como guichê burocrático ${ }^{35}$.

O contato não programado do usuário passa a se dar com um profissional (e não com um recepcionista), que realizará a missão difícil de, simultaneamente, acolher e escutar de forma qualificada e individualizada; fazer uma avaliação de riscos e vulnerabilidades biológicas, epidemiológicas e psicossociais; rediscutir e processar essa demanda juntamente com o usuário, tentando localizar qual é ou quais são os problemas; acionar outros membros da equipe responsável pelo cuidado daquele paciente para, conjuntamente, se necessário, resolver ou dar seguimento aos cuidados possíveis. Isso requer uma prática profissional com importante grau de comunicação, interpretação e negociação interdisciplinar ecom os usuários, estimulando o vínculo, acal mando ansiedades e buscando soluções.

Obviamente, há que compatibilizar agendas de médicos e enfermeiras para essa demanda de Acolhimento, pois eles são requisitados para supervisionar tal avaliação, negociação e prosseguimento do cuidado. Tal proposta depende de uma abertura dos profissionais para um compartilhamento de responsabilidades e decisões, respeitados os "núcleos de competência" 36 de cada profissão, mas flexibilizando os rituais típicos de consultas e procedimentos, de decisão clínica e de avaliação de risco/vulnerabilidade. Quanto mais flexíveis e versáteis os profissionais, quanto mais diversificadas e pouco ritualizadas suas ações, quanto mais misturadas e trabalhando juntas as pessoas, quanto mais aberto eacessível o serviço a todos os tipos de demanda, maior a possibilidade de a equipe imergir no mundo sociocultural de sua área de abrangência, de trocar saberes pessoais e profissionais, de realizar melhor 0 Acolhimento egarantir 0 acesso. 0 que não significa perder de vista grupos prioritários, fazer busca ativa, vigilância e promoção da saúde.

O funcionamento do Acolhimento cria a necessidade de ampliar a oferta de serviços e de cuidados na APS: se só se dispõe de consultas de médicos e enfermeiros, só se poderá oferecer isso aos usuários e nunca haverá o suficiente. M as é possível e desejável a oferta e invenção de outros rituais de encontro, outros settings terapêuticos, individuais e coletivos. Tal diversificação dos serviços énecessária e devehaver um estímulo institucional para sua construção. O utra necessidade éum processo constante de educação permanente e capacitação clínica para os profissionais não médicos, que comumente não exercitam sua clínica com tamanha responsabilidade e participação na avaliação e decisão de cuidados.

U ma mudança fundamental envolvida nas propostas de Acolhimento é que para organizar 
deforma sustentável um serviço com Acolhimento, que faça ações programadas e atividades coletivas, são necessárias modalidades de gestão participativa. É a própria equipe que pode avaliar e decidir responsavelmente quais as ações a serem ofertadas à população, e para isso énecessária a construção de uma cultura e um espaço próprios para a organização do trabal ho cotidiano, de forma democrática, fazendo cogestão entre as demandas e diretrizes institucionais ${ }^{37}$. A forma organizacional recomendada para isso é uma reunião semanal da equipe de referência para discutir, avaliar e gerir o trabal ho, a rotina deagendamento, acolhimento, visitas domiciliares, grupos, elaboração e avaliação de projetos terapêuticos individuais decasos complexos, problemas sanitários e sociais coletivos, demandas epidemiológicas etc., da qual participam todos os membros da equipe de saúde da família.

O bserva-sequea abertura das equipes à pressão da demanda costuma produzir angústia, carga exaustiva de trabalho e estresse emocional. Isso deve ser considerado, e a gestão local deve buscar formas de proteção para a equipe, de modo a permitir que prossiga lidando com a demanda e com a realidade sofrida da população brasileira. A poio humano, emocional einstitucional para a equipe é necessário, assim como facilitar a construção de clima de equipe, de corresponsabilização e de parceria entre os profissionais; e sua educação permanente. Além disso, outro importante esquema de proteção dos profissionais é a responsabilização limitada. Recomenda-seque o Acolhimento e a responsabilidade devam ser personalizados e referentes à coorte depacientes adscrita a cada equipe. Assim, o AcoIhimento tende a lidar com pessoas conhecidas com problemas conhecidos, ainda que complexos. Este fator tende a diminuir o estresse da avaliação de risco/vulnerabilidade e a facilitar a corresponsabilização entre equipe e usuários. Pacientes de outras áreas de abrangência aparecerão, mas serão avaliados e devolvidos para suas equipes dereferência.

D esnecessário dizer que a participação popular na gestão do serviço, através dos Conselhos deSaúde, pode ser de grande relevância na negociação dos termos elimites do Acolhimento, que costumeiramente envolve fatores tanto internos ao serviço quanto político-institucionais que transcendem a equipe de saúde da família, como contratação de profissionais, espaço físico, horários etc.
Acolhimento edesmedicalização: uma estratégia possível

A pressão da demanda espontânea tende, em geral, a acabar em atendimento médico. Os usuários assim o desejam, muita vez os técnicos e enfermeiras não têm alternativa, afinal é do médico a maior responsabilidade de diagnose e terapêutica. $O$ "núcleo de competência" clínica do médico é mais amplo do que o de outros profissionais de saúde. No entanto, a escuta, a avaliação de risco/ vulnerabilidade, a orientação, a resolução de problemas e o cuidado fazem parte do "campo de competência" de todos os profissionais.

Se a atividade profissional utiliza-se desses "núcleos de competência" para justificar a burocratização, se há pactos perversos que alimentam o não cuidado, se não há espírito de equipe e de trabalho multiprofissional, o Acolhimento tende a transformar-se em PA. N esse caso, a medicalização tende a avançar e se difundir.

0 apoio gerencial ea existência de profissionais em número suficiente são necessários e essenciais para possibilitar um contexto que facilite o Acolhimento, ainda que esta suficiência não garanta qualidade "desmedicalizadora". Trata-se de uma construção e um aprendizado difícil, que pode ser facilitado e até induzido, mas depende dos profissionais. A habilidadeclínicaéum fator importante, mas o trabalho conjunto em equipe, a construção de projetos terapêuticos e avaliações de riscos/vulnerabilidades individuais e coletivas e a própria discussão do problema da medicalização podem ajudar muito. Há que se trabal har continuadamente com os profissionais para "desmedicalizar" a atenção à saúde.

Durante o Acolhimento na APS seria possível uma prática voltada para a desmedicalização? Boa parte da demanda não programada é caracterizada por problemas de saúde medical izados, que chegam aos serviços de saúde em consequência da mídia, da cultura do consumismo, do medo e da insegurança. A experiência com o Acolhimento mostra queessa influência égrande na demanda do usuário. Mostra ainda que o espaço do acolhimento pode ser mais ou menos medicalizante na medida em que trabalha a sensibilidade do usuário e do profissional não médico em relação ao problema, em vez de usar esse momento para apenas fornecer a tecnologia médica.

Na prática da APS, muito próxima da vida cotidiana da comunidade, é difícil enquadrar muitos dos problemas trazidos pelos usuários em classificações diagnósticas precisas, o que facilita a desmedicalização. Se o médico tem uma 
tendência geral a medicalizar os problemas trazidos, alguns profissionais, por maior contato com o contexto de vida dos usuários ( principalmente Agente Comunitário de Saúde e técnicos de enfermagem), têm um potencial maior para uma abordagem ampliada desses problemas, trazendo elementos da vida familiar e social, em alguma medida favorecendo a desmedicalização do diagnóstico eda terapêutica, ao relativizar a abordagem biologicista.

Além disso, o médico pode funcionar como ator desmedicalizante e contribuir para ampliar a abordagem, já quetem mai or legitimidade para criticar o consumismo e a informação da mídia, acalmar ansiedades e apoiar iniciativas desmedicalizantes, reforçando a autoestima e o respeito interprofissional, o espírito de equipe e o vínculo do paciente com os outros membros da equipe. Por isso, a forma singular como as equipes trabal ham o Acolhimento éfundamental para definir o grau de medicalização do Acolhimento. 0 cuidado continuado e a responsabilização pelo acompanhamento dos pacientes, que implica conhecê-los progressivamente, seu contexto e dinâmica psicossocial, econômica e cultural, são um poderoso mecanismo para o aprendizado de uma clínica desmedicalizante. Perceber a relação entre medicalização, o retorno repetido excessivo ea iatrogenia faci lita a crítica à clínica centrada na doença e o aprendizado cotidiano sobre desmedicalização.

Isso sugere fortemente a realização do AcoIhimento por área de abrangência, ou seja, que cada equipe acolha os usuários pel os quais é responsável. Discutir os casos conjuntamente em vez de simplesmente basear-se em protocolos e fluxogramas também facilita uma abordagem ampliada dos problemas. Já o inverso tende a ocorrer nas práticas queutilizam demasiadamente os fluxogramas e protocolos rígidos. 0 encaminhamento excessivo para outros profissionais, que começam todo o cuidado de novo, tende ao reforço da lógica hegemônica e à fragmentação do cuidado.

Quando as narrativas dos usuários são monopolizadas pelo médico, mesmo que ele exerça uma clínica ampliada, somenteele perceberá com o tempo as fortal ezas e as fragilidades do modelo biomédico e as brechas que poderiam ser preenchidas ou expandidas por outros profissionais ou abordagens. Todavia, mesmo com todos esses cuidados, há uma tendência permanentee persistente do Acolhimento em centralizar-seno médi- co, até pelo poder de seu núcleo de competências e pela sua grande demanda numa sociedade já relativamente muito medicalizada. Por isso, os espaços de reunião da equipe devem ser utilizados para corrigir rumos e discutir dificuldades.

Além disso, o ambienteda APS permiteo contato com a cultura popular e técnicas e curadores não científicos, muitos dos quais podem proporcionar interpretações e cuidados de baixo risco, culturalmente adequados, acessíveis e por vezes surpreendentemente eficazes. Basta lembrarmo-nos da "eficácia simbólica" descrita por Lévy-Strauss ${ }^{38}$, cuja tradução biomédica restringiu-se ao reconhecimento do "efeito placebo", o qual, no entanto, não gerou know-how sobre como o médico aumentar, utilizar ou induzir tal efeito nos pacientes.

Por último, valecomentar o Acol himento realizado em unidades de saúde que congregam muitas equipes de saúde da família. N ão raramente ocorre aí a organização de um Acolhimento único, que atende a pacientes detodas as áreas de abrangência por meio deum revezamento de profissionais das equipes al i sediadas. Na prática, esse acolhimento fica voltado para demandas agudas e mantém as equipes no cuidado continuado. Observamos neste desenho a mesma tendência medicalizante do PA, já que se criam como que dois serviços, com lógicas distintas, na mesma unidade: um voltado para a doença, as intercorrências e o sintoma e, assim, mais medicalizante; outro que realiza ações programáticas, promoção e educação à saúde para uma parte da população usuária. A vantagem desse modelo em relação ao serviço deemergência exclusivo équeelepodeabrir rapidamente ao usuário as portas da sua equipe se é necessário um seguimento para seu caso.

Diferentemente, observamos que o Acolhimento realizado pela própria equipe de referência permitetransformá-lo, com o tempo, em mais um momento de cuidado, com possibilidade de se integrar ao relacionamento equipe-usuário. Em razão da nossa experiência, recomendamos, em geral, que as equipes de saúde da família trabalhem em um duplo registro, com atividades de pronta atenção e de cuidado continuado e programado $26,28,35$.

Reconhecemos a necessidade de selidar com a demanda espontânea ecom o inesperado na APS, eque a expansão das experiências de Acolhimento tem se demonstrado eficaz nesse particular. Sugerimos, contudo, reflexão continuada sobre a relação entre Acolhimento emedicalização. 


\section{Colaboradores}

CD Tesser foi o responsável pela concepção e re dação inicial do artigo e participou, juntamente com PP N eto e GWS Campos, das sucessivas ampliações, reduções, revisões críticas, formatação e redação final.

\section{Referências}

1. Vasconcelos CM. Paradoxos da mudança no SUS [tese]. Campinas: U nicamp; 2005. [acessado 2010 out 22]. Disponível em: http://libdigi.unicamp.br/ document/?code $=v t \mid s 000351668$.

2. Campos GWS. Reforma política e sanitária: a sustentabilidade do SUS em questão? Cien Saude Colet 2007; 12(2):301-307.

3. Illich I. A expropriação da saúde: nêmesis da medicina. 4å ed. São Paulo: N ova Fronteira; 1981.

4. Nogueira RP. A saúde pelo avesso. Natal: Seminare Editora; 2003.

5. Tesser CD. M edicalização social (I): o excessivo sucesso do epistemicídio moderno na saúde. Interface - Comunic, Saúde, Educ 2006; 10(19):61-76.

6. Poli Neto P. A medicalização da beleza [dissertação]. Florianópolis: Universidade Federal de Santa Catarina; 2006. [acessado 2010 out 22]. Disponível em: http://www.tede.ufsc.br/teses/PSPB0122.pdf

7. Andrade LOM, Bueno ICC, Bezerra RC. Atenção Primária à Saúde e Estratégia de Saúde da Família In: Campos GWS, M inayo M CS, Akerman, M, Drumond Júnior M, Carvalho YM. Tratado de Saúde Coletiva. São Paulo: Hucitec; 2006. p. 783-832.

8. Brasil. Ministério da Saúde. Política Nacional de Humanização: a humanização como eixo norteador das práticas de atenção e gestão em todas as instâncias do SU S. Brasília: M inistério da Saúde; 2004. [acessado 2010 out 22] Disponível em: http://dtr2004. saude.gov.br/susdeaz/instrumento/arquivo/04_ Cartilha_H umanizaSU S.pdf

9. Nye RA. The evolution of the concept of medicalization in the late twentieth century. Journal of History of the Behavioral Sciences 2003; 39(2):115-129.

10. Foucault M. História da sexualidade: a vontade de saber. vol. 1. Rio de Janeiro: Graal; 1988.

11. Foucault M. O nascimento da clínica. 5a ed. Rio de Janeiro: Forense Universitária; 2003.

12. Camargo Jr. KR. Biomedicina, ciência \& saber: uma abordagem crítica. São Paulo: Hucitec; 2003.

13. Tesser CD. A biomedicina e a crise da atenção à saúde: um ensaio sobre a desmedicalização [dissertação]. Campinas: Unicamp; 1999. [acessado 2010 out 22] Disponível em: http://libdigi.unicamp.br/document/ ?code=vtls000199171

14. Tesser CD. Medicalização social (II): limites biomédicos e propostas para a clínica na atenção básica. Interface - Comunic, Saúde, Educ 2006; 10(20):347362.

15. Canguilhem G. O normal e o patológico. Rio de Janeiro: Forense Universitária; 1978.

16. Freidson E. Profession of medicine: a study of the Sociology of applied knoledge. $2^{\text {nd }}$ ed. Chicago: The University of Chicago Press; 1988.

17. Williams SJ, Calnan M. The "limits" of medicalization?: modern Medicine and the lay populace in "late" modernity. Social Science and Medicine 1996; 42(12):1609-1620.

18. Moynihan R, Smith R. Too much Medicine? British Medical Journal 2002; 324(7342):859-860. 
19. Illich I. Un facteur pathogène prédominant: I'obsession de la santé parfaite. Le M onde Diplomatique 1999; 28 mar. [acessado 2010 out 22] Disponível em: http://www.monde-diplomatique.fr/1999/ 03/ILLICH/11802.html\#nh5

20. Nogueira RP. Higiomania: a obsessão com a saúde na sociedade contemporânea. In: Vasconcelos EV. A saúde nas palavras e nos gestos: reflexões da rede educação popular e saúde. São Paulo: Hucitec; 2001. p. 63-72.

21. Castiel LD, Diaz CAD. A saúde persecutória: os limites da responsabilidade. Rio de Janeiro: Editora Fiocruz; 2007.

22. Brasil. Ministério da Saúde. Política Nacional de Atenção Básica. Brasília: M inistério da Saúde; 2006. [acessado 2010 out 22]. Disponível em: http://portal. saude.gov.br/portal/arquivos/pdf/politica_nacional_ atencao_basica_2006.pdf

23. Schraiber LB, örganizador. Programação em saúde hoje. 2ª ed. São Paulo: Hucitec; 1990.

24. M endes EV, organizador. Distrito sanitário. São Paulo: Hucitec; 1993.

25. Cunha GT. A construção da clínica ampliada na atenção básica. São Paulo: Hucitec; 2005.

26. Campos GWS. A saúde pública e a defesa da vida. São Paulo: Hucitec; 1991

27. M erhy EE. A rede básica como uma construção da saúde pública e seus dilemas. In: M erhy EE, Onocko R, organizadores. Agir em saúde: um desafio para o público. São Paulo: Hucitec; 1997. p. 197-228.

28. Campos GWS, M erhy EE, Nunes E. Planejamento sem normas. São Paulo: Hucitec; 1989.

29. N ovaes H N. A ções integradas nos sistemas locais de saúde - SILOS. São Paulo: Biblioteca Pioneira; 1992.

30. M erhy EE. Em busca da qualidade dos serviços de saúde: os serviços de porta aberta para a saúde e 0 modelo técnico assistencial em defesa da vida. In: Cecílio LC, organizador. Inventando a mudança na saúde. São Paulo: Hucitec; 1994. p.117-160.
31. Green A, Duncan R, M irzoev T. Primary Health Care and England: the coming of age of Alma Ata? Journal Health Policy 2006; 80(1):11-31.

32. Starfield B. Atenção Primária: equilíbrio entre necessidades de saúde, serviços e teconologia. Brasília: Unesco/M inistério da Saúde; 2002.

33. Franco TB, Bueno WS, M erhy EE. Acolhimento e os processos de trabalho em saúde: 0 caso de Betim/M G. Cad Saude Publica 1999; 15(2):345-353.

34. Guardini R. Ética do Acolhimento. Revista THOT 2002; 77:63-69.

35. Campos GWS. Saúde Paidéia. São Paulo: Hucitec; 2003.

36. Campos GWS. Saúde Pública e Saúde Coletiva: campo e núcleo de saber e prática. Cien Saude Colet 2002; 5(2):219-230.

37. Campos GWS. U m método para análise e co-gestão de coletivos: a constituição do sujeito, a produção de valor de uso e a democracia em instituições: o método da roda. Campinas: Hucitec; 2000.

38. Lévi-Strauss C. 0 pensamento selvagem. $2^{2 a}$ ed. São Paulo: Companhia Editora Nacional; 1976.

Artigo apresentado em 26/10/2007

A provado em 27/06/2008

Versão final apresentada em 06/08/2008 